\title{
A study on the effect of chemically synthesized magnetite nanoparticles on earthworm: Eudrilus eugeniae
}

\author{
Antony V. Samrot ${ }^{1} \cdot$ C. Justin ${ }^{1} \cdot$ S. Padmanaban ${ }^{1} \cdot$ Ujjala Burman $^{1}$
}

Received: 6 July 2016/ Accepted: 26 November 2016/Published online: 1 December 2016

(C) The Author(s) 2016. This article is published with open access at Springerlink.com

\begin{abstract}
Most look into the benefits of the nanoparticles, but keeping aside the benefits; this study focuses on the impacts of nanoparticles on living systems. Improper disposal of nanoparticles into the environment is a subject of pollution or nano-pollution which in turn affects the flora and fauna in the ecosystem, particularly soil ecosystem. Thus, this study was done to understand the impacts of chemically synthesized magnetite nanoparticles on earthworm-Eudrilus eugeniae, a soil-dependent organism which acquires food and nutrition from decaying matters. The chemically synthesized magnetite nanoparticles were characterized by UV-visible spectrophotometry, Fourier transform infrared spectroscopy and field emission scanning electron microscopy. Earthworms were allowed to interact with different concentrations of synthesized nanoparticles and the effect of the nanoparticles was analysed by studying the phenotypic changes followed by histology and inductively coupled plasma optical emission spectrometry analyses.
\end{abstract}

Keywords Nano-pollution - Magnetite nanoparticles · Eudrilus eugeniae · ICP-OES · Histology

Antony V. Samrot

antonysamrot@gmail.com

1 Department of Biotechnology, Sathyabama University, Jeppiaar Nagar, Rajiv Gandhi Salai, Sholinganallur, Chennai 600 119, India

\section{Introduction}

Nanotechnology is one the fastest growing fields in recent times. Nanoparticles are materials that have a typical size ranging from 1 to $100 \mathrm{~nm}$. It has been applied in almost all the latest inventions right from computers to drug delivery systems (Yu et al. 2015). There are several metal nanoparticles available; amongst all, magnetite is most attractive, since it has applications in industry as well as in the medical field. Magnetite nanoparticles have been utilized in ultrasonography (Liu et al. 2006), magnetic resonance imaging (Pankhurst et al. 2003), magnetic sensing (Thurn-Albrecht et al. 2000) and in the wastewater treatment process (Tiwari et al. 2008). The application of nanoparticles is useful not only to medicine and treatment, but also in the field of agriculture for sustained growth of plants where it acts as carrier ions (Mukhopadhya 2014). There are several other applications of nanoparticles which add on to its positive side, but on the other hand it can cause pollution and toxic effects with improper handling, leading to hazardous effects to living organisms and the environment. The government of most countries has established a set of principles for the use, disposal, and treatment of nanoparticle wastes, and these principles belong more or less to the same dimension with alterations depending on the type of nanoparticle being synthesized or the level of contamination risk. Improper disposal of nanoparticles has witnessed a steep rise from 2005 to 2010 (Lee et al. 2010). The Centre for Knowledge Management of Nanoscience and Technology and the Government of India together have submitted a report on "Guidelines and best practices for safe handling of nanomaterials in research laboratories and industries" (http://nanomission.gov.in). It explains the various precautionary steps to be taken during synthesis and handling 
of nanoparticles, waste disposal methods, and cleaning procedures. Even though these guidelines have been established, improper disposal of nanomaterials is still practised. Increased use and improper disposal of products containing nanoparticles are inevitably resulting in dissemination of nano-waste into aquatic and terrestrial ecosystems (MacCormack and Goss 2008), causing severe impacts on soil-living organisms and may also lead to a total extinction of organisms especially earthworms. Several animal models such as mice and fish are often used, but using smaller animals like earthworms is time saving and helps to find the impacts of nanoparticles (Exbrayat et al. 2015). Earthworms have been extensively used to study the toxic effects of nanoparticles and gives us an outline of the impacts caused by the produced nanoparticles. Qi (2009) found $\mathrm{ZnO}$ nanoparticles to exhibit toxic effects on earthworms, which was observed by filter paper (acute test) and artificial soil test (chronic test). Hu et al. (2010) found significant DNA damage by comet assay in $\mathrm{TiO}_{2}$ and $\mathrm{ZnO}$ nanoparticles-exposed earthworms.

Magnetite nanoparticles have found tremendous applications which include cell separation, arsenic removal from water, DNA separation, MRI, etc. (Hai et al. 2008). Most nanoparticles including magnetite reach the environment without proper prior treatment; this might cause impacts on soil organisms. Thus, this work was done to study the impacts caused by magnetite nanoparticles on earthworm-Eudrilus eugeniae. Here, the nanoparticles were produced by the chemical co-precipitation method and characterized by UV-Vis, FTIR, and FeSEM analyses. The produced nanoparticles were allowed to interact directly with the earthworm at nanogram concentrations. The impact of the nanoparticles was evaluated by histology and ICP-OES analyses.

\section{Materials and methods}

\section{Materials required}

All chemicals used in this study were of analytical grade. Tetramethyl ammonium hydroxide (TMAOH) was obtained from Spectrochem, India. Iron(III) chloride hexahydrate $\left(\mathrm{FeCl}_{3} \cdot 6 \mathrm{H}_{2} \mathrm{O}\right)$ and iron(II) sulphate heptahydrate $\left(\mathrm{FeSO}_{4} \cdot 7 \mathrm{H}_{2} \mathrm{O}\right)$ were purchased from Thomas Baker PVT Limited, India, and Qualigens Fine Chemicals, India, respectively. Acetone and formaldehyde were obtained from Merck, India. Nitric acid and hydrochloric acid were obtained from Rankem, India. For the synthesis procedure, nitrogenated milli-Q water was utilized to minimize the aggregation due to oxidation effects on the nanoparticle.

\section{Synthesis of nanoparticles}

Nanoparticles were synthesized by modified chemical reduction-precipitation method of Andrade et al. (2012) and Mascolo et al. (2013) with some modifications. $0.1 \mathrm{~g}$ of $\mathrm{FeSO}_{4} \cdot 7 \mathrm{H}_{2} \mathrm{O}$ and $0.1 \mathrm{~g}$ of $\mathrm{FeCl}_{3} \cdot 6 \mathrm{H}_{2} \mathrm{O}$, were weighed and each chemical was separately dissolved, respectively, in $1 \mathrm{ml}$ of nitrogenated double-distilled water. $100 \mu \mathrm{l}$ of the above mixture was added drop by drop to $100 \mu \mathrm{l}$ of TMAOH and vortexed. $20 \mu \mathrm{l}$ of the resultant black precipitate was washed with water to remove the traces of TMAOH and further dissolved in $1.5 \mathrm{ml}$ formaldehyde and centrifuged at $10,000 \mathrm{rpm}$ for $10 \mathrm{~min}$; the pellet was collected and added with $280 \mu \mathrm{l}$ nitrogenized milliQ water.

\section{Characterization of nanoparticles}

\section{UV-visible spectrophotometer analysis}

The UV-visible analysis was done in UV-1800 spectrophotometer (Shimadzu, Japan), having deionized water as blank. The cuvette was loaded with $1 \mathrm{ml}$ of the prepared nanoparticle solution and mounted on the sample holder. The UV absorption maximum was determined between the range of 200 and $750 \mathrm{~nm}$.

\section{Fourier transform infrared spectroscopy (FTIR) analysis}

The IR spectrum was recorded using IR Affinity-1s (Shimadzu, Japan) instrument for the prepared nanoparticles. Nanoparticles were coated over a $\mathrm{KBr}$ thin film and reading was recorded with transmission mode scan in the spectral region of $4000-400 \mathrm{~cm}^{-1}$.

\section{Field emission scanning electron microscopy (FeSEM) analysis}

Field emission scanning electron microscope is performed to get a clear shape and size of the synthesized nanoparticles. The sample was washed with nitrogenized deionized water five times to remove traces of formaldehyde. The sample was air dried to remove moisture content. The dried sample was then mounted on 1 in.-sized sample holder using carbon putting adhesive process. Images of field emission scanning electron microscope were taken using SUPRA55 (Carl Zeiss, Germany).

\section{Earthworm collection, maintenance, and pre- treatment}

The earthworm species E. eugeniae was obtained from Solid Waste Management, Mahabalipuram. Eudrilus eugeniae are also known by their much common name 
Fig. 1 UV-visible spectrophotometric analysis of magnetite nanoparticles
Fig. 2 FTIR analysis of magnetite nanoparticles
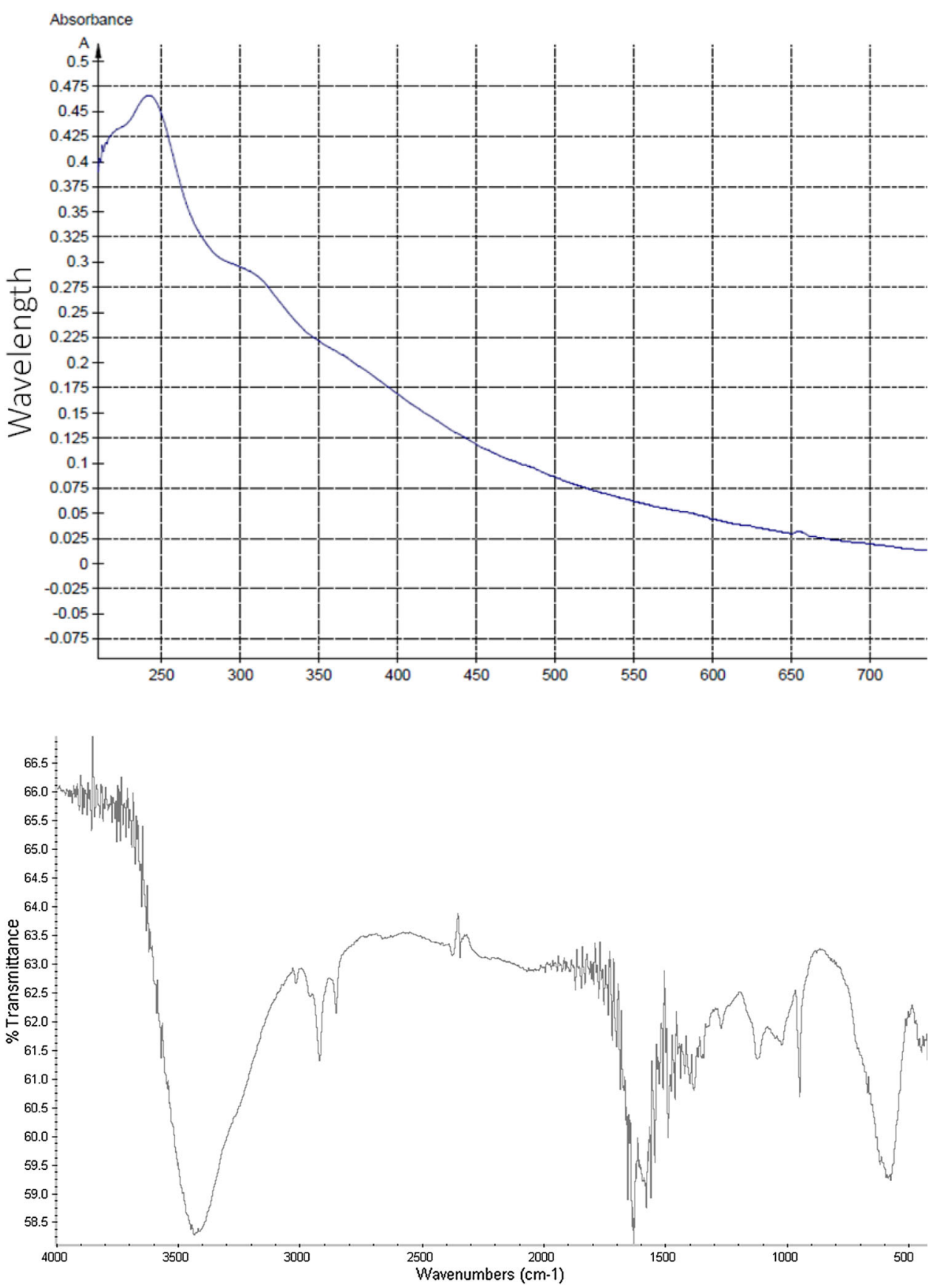

African night crawler, a native of the African continent with the ability to grow in a warm climate of around $25-30{ }^{\circ} \mathrm{C}$. The epigeic nature and the faster reproduction cycle of the animal were the reasons for its use in this study (Butt and Lowe 2010). All the earthworms were allowed to crawl freely over a raft of wet tissue papers sprayed with distilled water so that all their impurities were removed, then ten earthworms/box $(16 \mathrm{~cm} \times 12 \mathrm{~cm} \times 7 \mathrm{~cm})$ were introduced and allowed to acclimatize to the laboratory environment. Dried cow dung was fed to the earthworms at regular intervals. The moisture conditions were also maintained in the box to provide adequate growing conditions for the earthworm (Sherman 2003). The setup was left undisturbed for 4-5 days for the earthworms to adjust to the environment of the box.

\section{Treatment with nanoparticles}

The earthworms were pre-treated as mentioned earlier. Magnetite nanoparticles were diluted in de-ionized water to have different concentrations (100, 200, and $400 \mathrm{ng}$ ) in $10 \mathrm{ml}$ de-ionized water. Ten earthworms were allowed to 


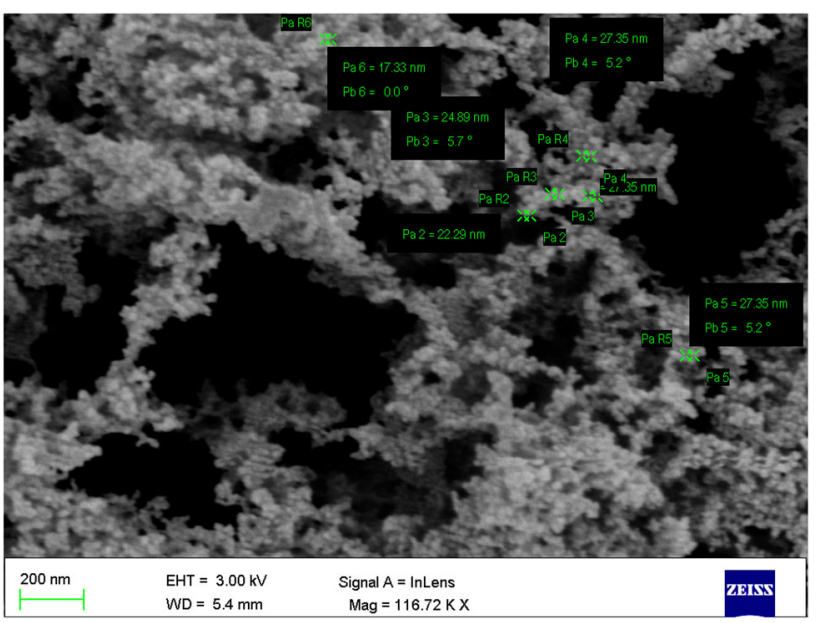

Fig. 3 FeSEM image of magnetite nanoparticles. The size of the particles was found to be between 17 and $28 \mathrm{~nm}$

interact for $1 \mathrm{~h}$ with their respective nanoparticle concentration $(10 \mathrm{ml})$ in a beaker. One set of control was not exposed to nanoparticles, but to de-ionized water alone. The above-mentioned experimental procedure was followed for 10 days. After the 10th day, five animals were dissected and subjected to histology and five were subjected to ICP-OES analysis.

\section{Analyses of nanotoxic effects on earthworms}

\section{Phenotypic changes}

The treated earthworms were observed for phenotypical changes such as colour change, morphological changes, and behavioural changes, as phenotypic changes of an organism are the first indication of damage to the organism. This phenotypic effect was observed on all ten animals used in this study and cumulative data are represented.

\section{Histology}

Five earthworms from control and each test groups were killed and the gut region along with the clitellum was dissected using a sterile surgical blade. The samples were immediately transferred to $10 \%$ formaldehyde solution and kept for $3 \mathrm{~h}$ to avoid tissue damage. The tissues were dehydrated through a series of ethanol washes to remove water traces, infiltrated with wax and then entrenched in paraffin. The fixed tissues were sliced using microtome into $1 \mu \mathrm{m}$ films and subjected to $\mathrm{H} \& \mathrm{E}$ staining (haematoxylin and eosin). Once the staining procedure was done, all the sections were visualized under microscopes and photographs were taken.

Inductively coupled plasma optical emission spectrometry (ICP-OES)

The dissolution of the five earthworm tissues from each concentration including the control was done following the method of Button et al. (2009) with some modification. The dissected pieces of the earthworms were added to $5 \mathrm{ml}$ of concentrated nitric acid and kept for $15 \mathrm{~min}$. After $15 \mathrm{~min}$, five to ten drops of concentrated hydrochloric acid were added to the samples and the mixtures were microwaved. The clear solution was taken for ICP-OES analysis. This analysis was performed to find the quantity of metal nanoparticles present in the body of the earthworm and the study was done at the Sophisticated Analytical Instrument Facility (SAIF), IITM, Chennai, using Perkin Elmer optima 5300 DV ICP-OES. The mean total magnetite nanoparticles were obtained and expressed in terms of mean $\pm \mathrm{s}$ tandard error.

\section{Results and discussion}

\section{Characterization of synthesized nanoparticles}

\section{UV analysis}

Synthesized magnetite nanoparticles showed absorbance maximum between 230 and $250 \mathrm{~nm}$ (Fig. 1); also, Wang et al. (2014) reported that magnetite nanoparticles showed their magnetite's absorbance maxima near $250 \mathrm{~nm}$.

\section{FTIR analysis}

Vibrational stretching band was found at $\sim 570$ corresponding to the $\mathrm{Fe}-\mathrm{O}$ bonding (Fig. 2); a similar stretch was seen by Kulkarni et al. (2014) in the magnetite prepared by co-precipitation of ferric chloride and ferrous chloride. 3400 and $1630 \mathrm{~cm}^{-1}$ are specific absorption bands for the remnant water molecules (Balacianu et al. 2009).

Table 1 Phenotypic changes observed in earthworm

\begin{tabular}{llllll}
\hline S. no & Parameter analysed & Control & 100 ng exposed & 200 ng exposed & B00 ng exposed \\
\hline 1. & Colour change & Nil & Brown & Brown & Nil black \\
2. & Behavioural change & Nil & Nil & Nil & Nil \\
3. & Death & Nil & Nil & Nil &
\end{tabular}



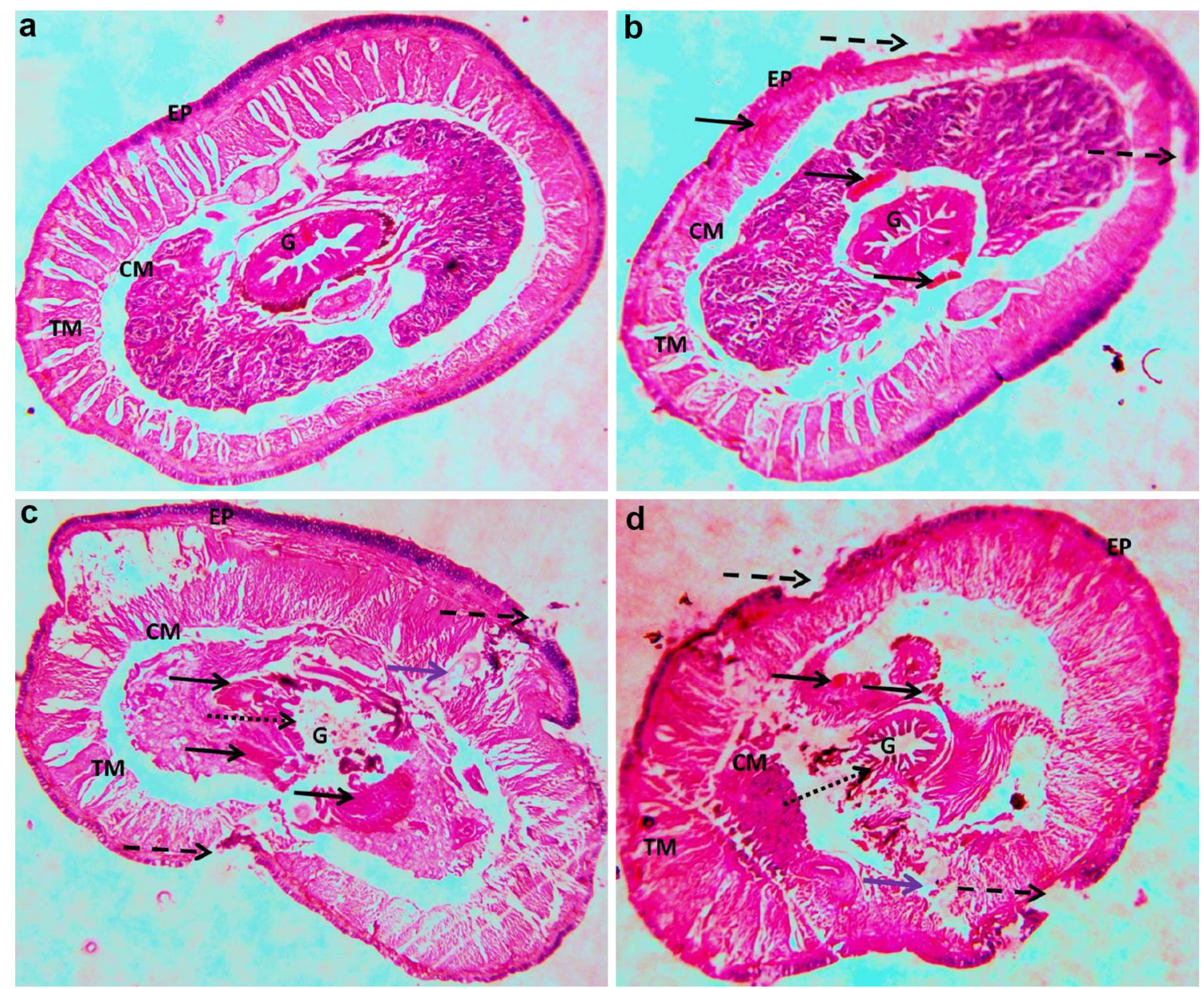

Fig. 4 H\&E staining of earthworm exposed to magnetite nanoparticle $E P$ epidermis, $C M$ circular muscle, $T M$ transverse muscle, and $G$ gut region. a Control, b100 ng/10 ml exposed, c $200 \mathrm{ng} / 10 \mathrm{ml}$, d $400 \mathrm{ng} / 10 \mathrm{ml}$ exposed. b-d Solid arrow shows the impact with

\section{SEM analysis}

The size of the magnetite produced in this study ranged between 17 and $28 \mathrm{~nm}$ (Fig. 3). The aggregation of the particles might be because of longer day storage. The magnetic particles synthesized in the presence of TMAOH are naturally very small in size (Lahive et al. 2014). Mascolo et al. (2013) also found perfect colloidal suspension of magnetite when TMAOH was used, but they did not find any sediment particles after several months of ageing.

\section{Nanotoxic effects on earthworm}

\section{Phenotypic changes}

No mortality was observed in either of the boxes, whereas the colour of the earthworm changed from light brown to dark brown/black (Table 1). Magnetic nanoparticle might have influenced the colour change of the earthworms. Since some granular lipofuscin-like deposits, $\mathbf{b}-\mathbf{d}$ erosion of the epithelium (dashed arrow), c, d with fibrosis of the circular muscle (purple arrow) and with gut disintegration (dotted arrow)

the nanoparticles are very small and could enter the epithelium of the earthworm easily, it would have caused an impact on the colour of the worm. Nanoparticles are internalized by TLR (toll like receptors), and a patternrecognition receptors (PRRs) of coelomic cell activates the coelomic cytolytic factor (CCF). CCF activates the prophenoloxidase (ProPO) cascade, which ends with melanin production. This melanization reaction is normally involved in defence mechanism and also forms brown bodies with nanoparticles (Yadav 2015). ZnO- and CuOtreated earthworms had reduction in weight and cocoon production (Alahdadi and Behboudi 2015). Silver nanoparticles were also found to show a negative influence over earthworm reproduction (Schlich et al. 2013).

\section{Haematoxylin and eosin staining}

Nanoparticle exposure leads to deposits of lipofuscin in the circular muscle. Erosion of the epithelium was seen in all 


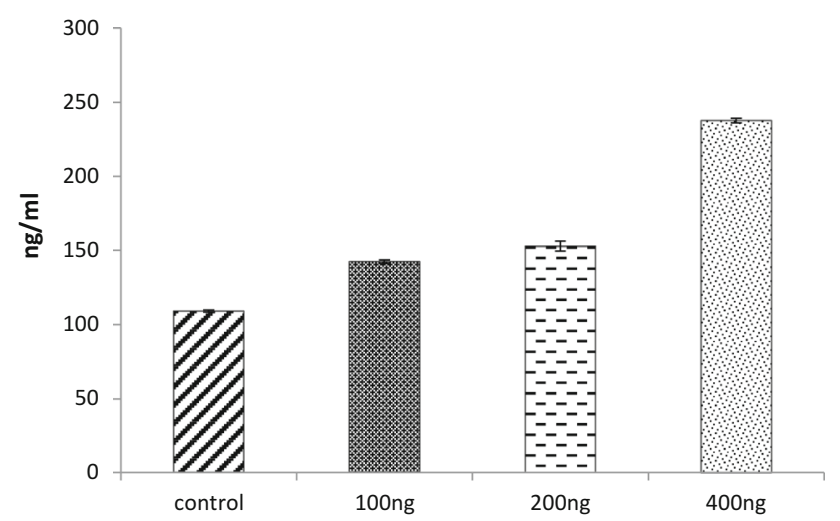

Fig. 5 ICP-OES analysis of earthworm tissue

the nanoparticles-exposed earthworms. Gut disintegration was seen in earthworms exposed to higher concentrations, i.e. 200 and $400 \mathrm{ng}$ (Fig. 4). Lahive et al. (2014) observed erosion of the epithelium of $\mathrm{CeO}_{2}$-treated Eisenia fetida; they also observed mucocyte proliferation and fibrosis and loss of architecture in the circular muscle. A similar kind of result was observed in Lumbricus rubellus earthworms exposed to silver nanoparticles by Ploeg et al. (2014). Silver nanoparticles were found to cause genotoxic effects, evidenced by increment of micronuclei coelomycetes frequency in the gut cells of A. caliginosa earthworms (Khalil 2016). Apoptotic cells were also observed in the cuticle and intestinal epithelium of Lumbricus terrestris exposed to silver nanoparticles (Lapied et al. 2010).

\section{Inductively coupled plasma optical emission spectrometry analysis}

The nanoparticle values were observed at $238.204 \mathrm{~nm}$ by ICP-OES analysis, where our sample's absorption spectrum was between 230 and $250 \mathrm{~nm}$ only. A smaller concentration of magnetite present in soil naturally (Longworth et al. 1979; Maher 1986), might have influenced the accumulation in the control earthworms. Increase in the concentration of nanoparticles increased the accumulation (Fig. 5). Schlich et al. (2013) found $7.0 \mathrm{mg} / \mathrm{kg}$ worms to $11.3 \mathrm{mg} / \mathrm{kg}$ worms concentrations of silver in earthworms exposed to silver nanoparticles. Gupta and Yadav (2014) observed using transmission electron micrography a large agglomeration of ZnO-NPs in coelomic fluid and tissues.

\section{Conclusion}

Magnetite nanoparticles were produced by the chemical co-precipitation method. The produced nanoparticles were found to be between 17 and $28 \mathrm{~nm}$ in size. The impact caused by nanoparticles exposure was found to be proportionate to the concentration. The animals' skin colour changed from brown to black with an increase in the nanoparticle concentration. Histological studies revealed the impact of nanoparticles exposure on the erosion of the epithelium, fibrosis of the circular muscle and also disintegration of the gut. ICP-OES study also confirmed the accumulation of magnetite nanoparticle in the animals' body. Thus, this study revealed the negative impacts of nanoparticles against the soil organism-E. eugeniae, and it suggests that proper disposal of the nanoparticles to the environment has to be regulated.

Acknowledgements The authors thank the Sathyabama University for their support.

\section{Compliance with ethical standards}

Conflict of interest The authors have no conflict of interest.

Open Access This article is distributed under the terms of the Creative Commons Attribution 4.0 International License (http:// creativecommons.org/licenses/by/4.0/), which permits unrestricted use, distribution, and reproduction in any medium, provided you give appropriate credit to the original author(s) and the source, provide a link to the Creative Commons license, and indicate if changes were made.

\section{References}

Alahdadi I, Behboudi F (2015) The effects of $\mathrm{CuO}$ and $\mathrm{ZnO}$ nanoparticles on survival, reproduction, absorption, overweight, and accumulation in Eisenia fetida earthworms tissues in two substrates. Intern J Environ Res 9(1):35-42 (winter 2015)

Andrade AL, Fabris JD, Ardissone JD, Valente MA, Ferreira JMF (2012) Effect of tetramethylammonium hydroxide on nucleation, surface modification and growth of magnetic nanoparticles. J Nanomater 2012:454759

Balacianu FD, Nechifora C, Bartos R, Voicu SI, Nechifor G (2009) Synthesis and characterization of $\mathrm{Fe}_{3} \mathrm{O}_{4}$ magnetic particlesmultiwalled carbon nanotubes by covalent functionalization. Optoelectron Adv Mater Rapid Commun 3:219-222

Butt KR, Lowe CN (2010) Controlled cultivation of endogeic and anecic earthworms. In: Karaca A (ed) Biology of earthworms, volume 24 of the series soil biology, pp 107-121

Button M, Watts MJ, Cave MR, Harrington CF, Jenkin GT (2009) Earthworms and in vitro physiologically-based extraction tests: complementary tools for a holistic approach towards understanding risk at arsenic-contaminated sites. Environ Geochem Health 31:273-282

Exbrayat JE, Moudilou EN, Lapied E (2015) Harmful effects of nanoparticles on animals. J Nanotechnol 2015:10

Guidelines and best practices for safe handling of nanomaterials in research laboratories and industries (Nano Mission, DST, Govt of India). http://nanomission.gov.in/What_new/Draft_ Guidelines_and_Best_Practices.pdf

Gupta S, Yadav S (2014) Bioaccumulation of ZnO-NPs in earthworm Eisenia fetida (Savigny). J Bioremediat Biodegrad 5:250

Hai NH, Chau N, Luong NH (2008) Applications of magnetite nanoparticles for water treatment and for DNA and cell separation. J Korean Phys Soc 53(3):1601-1606 
Hu CW, Li M, Cui YB, Li DS, Chen J, Yang LY (2010) Toxicological effects of $\mathrm{TiO} 2$ and $\mathrm{ZnO}$ nanoparticles in soil on earthworm Eisenia fetida. Soil Biol Biochem 42:586-591

Khalil AM (2016) Physiological and genotoxic responses of the earthworm Aporrectodea caliginosa exposed to sublethal concentrations of AgNPs. J Basic Appl Zool 74:8-15

Kulkarni SA, Sawadh PS, Palei PK (2014) Synthesis and characterization of superparamagnetic $\mathrm{Fe}_{3} \mathrm{O}_{4} @ \mathrm{SiO}_{2}$ nanoparticles. J Korean Chem Soc 58:100-104

Lahive E, Jurkschat C, Shaw BJ, Handy RD, Spurgeon DJ, Svendsen C (2014) Toxicity of cerium oxide nanoparticles to the earthworm Eisenia fetida: subtle effects. Environ Chem 11:268-278

Lapied E, Moudilou E, Exbrayat JM, Oughton DH, Joner EJ (2010) Silver nanoparticle exposure causes apoptotic response in the earthworm Lumbricus terrestris (Oligochaeta). Nanomedicine 5(6):975-984

Lee WM, Kim SW, Kwak JI, Nam SH, Shin YJ, An YJ (2010) Research trends of ecotoxicity of nanoparticles in soil environment. Toxicol Research 26(4):253-259. doi:10.5487/TR.2010. 26.4.253

Liu J, Levine AL, Matton JS, Yamaguchi M, Lee RJ, Pan X, Rosol TJ (2006) Nanoparticles as image enhancing agents for ultrasonography. Phys Med Biol 51:2179-2189

Longworth G, Becker LW, Thompson R, Oldfield F, Dearing JA, Rummery TA (1979) Mössbauer effect and magnetic studies of secondary iron oxides in soils. J Soil Sci 30:93-110

MacCormack TJ, Goss GG (2008) Identifying and predicting biological risks associated with manufactured nanoparticles in aquatic ecosystems. J Ind Ecol 12(3):286-296

Maher BA (1986) Characterisation of soils by mineral magnetic measurements. Phys Earth Planet Inter 42:76-92

Mascolo MC, Pei Y, Ring TA (2013) Room temperature coprecipitation synthesis of magnetite nanoparticles in a large $\mathrm{pH}$ window with different bases. Materials 6:5549-5567
Mukhopadhya SS (2014) Nanotechnology in agriculture: prospects and constraints. Nanotechnol Sci Appl 7:63-71

Pankhurst QA, Connolly J, Jones SK, Dobson J (2003) Applications of magnetic nanoparticles in biomedicine. J Phys D Appl Phys 36:R167-R181

Ploeg MJCV, Handy RD, Waalewijn-kool PL, Van Den Berg JHJ, Rivera ZEH, Bovenschen J, Molleman B, Baveco JM, Tromp P, Peters RJB, Koopmans GF, Rietjens IMCM, Van Den Brink NW (2014) Effects of silver nanoparticles (nm-300 k) on Lumbricus rubellus earthworms and particle characterization in relevant test matrices including soil. Environ Toxicol Chem 33:743-752

Qi B (2009) Acute and reproductive toxicity of nano-sized metal oxides $\left(\mathrm{ZnO}\right.$ and $\left.\mathrm{TiO}_{2}\right)$ to Earthworms (Eisenia fetida). M.D. Dissertation, Texas Tech University, Texas

Schlich K, Klawonn T, Terytze K, Hund-rinke K (2013) Effects of silver nanoparticles and silver nitrate in the earthworm reproduction test. Environ Toxicol Chem 32:181-188

Sherman R (2003) Raising earthworms successfully. North Carolina Cooperative Extension Service, EBAE. 103-83

Thurn-Albrecht T, Schotter J, Kastle GA, Ley N et al (2000) Ultrahigh-density nanowire arrays grown in self-assembled diblock copolymer templates. Science 290:2126-2129

Tiwari DK, Behari J, Sen P (2008) Application of nanoparticles in waste water treatment. World Appl Sci J 3(3):417-433

Wang X, Niessner R, Knopp D (2014) Magnetic bead-based colorimetric immunoassay for aflatoxin B1 using gold nanoparticles. Sensors 14(11):21535-21548

Yadav S (2015) Presence of Au-NPs in coelomic cells of earthworm Eudichogaster prashadi Stephenson. Int J Curr Microbiol Appl Sci 4(1):1013-1021

Yu J, Zhou Y, Chen W, Ren J, Zhang L, Lu L, Luo G, Huang H (2015) Preparation, characterization and evaluation of $\alpha$-tocopherol succinate-modified dextran micelles as potential drug carriers. Materials 8:6685-6696 